\title{
Enhancing Lighted Navigational Aids Using GIS Mapping
}

\author{
Gamal Abouelenean, PhD, PE \\ College of Engineering and Applied Sciences \\ Stony Brook University \\ Stony Brook, NY 11794 \\ U.S.A \\ gamal.abouelenean@stonybrook.edu
}

\begin{abstract}
This paper proposes a methodology to help navigate more safely using GIS Mapping. A proposed methodology can build up lit maps to most bay areas and port entrances. A detailed description of the range ring methodology is given and recommendations are drawn. It is concluded that the mapping of a lit area will help revision and maintenance of existing withdraws of bay lighting. A practical implementation of the methodology is applied to Great South Bay area in New York. Results show that there is a need to increase the buoys light and revise existing buoys locations in order to make night navigation through the bay safer.
\end{abstract}

Keywords-component; GIS; navigation; mapping; port; GPS

\section{INTRODUCTION}

In the maritime environment it can be very difficult to determine your location at night. In daytime hours there are buoys and landmarks that allow mariners to determine their location. At night, many of these buoys are not lighted and landmarks are often not visible except on the clearest nights with full moon. There have been, for many years, charts that show coastlines, bathymetry, navigation aids, and other landmarks to help determine location.

In recent years great advances have been developed in the area of satellite positioning using Global Positioning Systems (GPS). The Global Positioning System (GPS) is a space-based radio navigation system that provides reliable positioning, navigation, and timing services to users on a continuous worldwide basis. For anyone with a GPS receiver, the system will provide location and time. GPS provides accurate location and time information for an unlimited number of users in all weather, day and night, anywhere in the world.

The GPS is made up of three parts: satellites; control and monitoring stations; and the GPS receivers owned by users. GPS satellites broadcast signals from space that are picked up and identified by GPS receivers. Each GPS receiver then provides three-dimensional location (latitude, longitude, and altitude) plus the time.
Geographical Information System (GIS) is one of the GPS dependent applications that help get a proper "fix" on your exact location using charts and maps. GPS have the ability to pinpoint your exact location anywhere on the planet down to ten feet (Approx. 3m) of accuracy in all 3 dimensions. Including some sort of basic map/chart that can be upgraded to show more and more detail, GIS far surpassing the information held on a "normal" chart, which was the standard for the last 100 years.

These new technologies have advanced marine navigation greatly in the last 15 years to the point where almost all of the tedious calculations and hand work is obsolete. The problem lies in the reliance of mariners on these technologies and expectation that they will always be there and accurate.

When unit loses power, or malfunctions, and with more and more wireless electronic devices, the chances that one or more of them will interfere with other signals is of great concern. Most likely a mariner would not even know if his GIS unit was off for few hundred feet or picking a signal from another nearby device.

These units should not be used as a crutch for mariners and to hide inability to properly navigate and determine their location based on their surroundings.

There are, and have been for many years, aids to navigation, mostly buoys to mark water ways and other marine landmarks, or watermarks. Now bring into the picture visibility, it is fairly simple to determine your location on a sunny day with a decent chart in most cases. When visibility decreases such as in a fog or during night time, buoys have lights that help the mariner to avoid collisions.

The range of these lights and distance apart can create dead spots on the water where no navigational aid can be seen. The problem initiated due to dead spots is where these spots are and how to find them. This paper discusses a methodology of applying GIS to determine the dead spots on a marine path 
with an application to the Great South Bay, off of the south shore of Long Island, NY.

\section{PROBLEM FORMUATION}

Few types of marine aids to navigation are set to determine bay and port entrance paths. These are mainly buoys and lights at the end of jetties, rock piles, and docks. These aids are regulated by rules set up by coast guard and naval authorities (world wide) in terms of their color, flashing pattern, shape, size, and locations. They have to be documented and resided in pre-specified locations for many years. The information regarding these aids to navigation is available from the responsible authority of navigation such as the US National Oceanic and Atmospheric Administration (NOAA). There are many different types of these aids involved in navigation and ultimately meet the requirements set forth by the responsible authority.

The buoys, as navigation aids, are either green or red color. The color denotes which side of the buoy is safe to travel on. They are also numbered in order from one end of a path to the other. Buoys are shaped according to their color and function, set forth by standards and regulations.

These distinct differences help to identify the buoys in many weather conditions as possible, by color, shape, or number. Many of these, but not all have lights on top of them. These lights flash the color of the buoy at night and times of low visibility and have distinct flashing patterns to help identification.

These buoys' light is powered by solar energy, completely encased in acrylic plastic and completely waterproof and have a life of 5 years. The optimum range of light is one nautical mile. The lights are mounted to the top of the buoys or on posts on end of docks, jetties, and rock piles.

In real world or in a lab these lights will be visible for almost one nautical mile in distance if the surrounding condition is perfect. Being fixed to a moving object, the lights cannot be seen for an exact one nautical mile. If the observers are in a vessel, they will be moving as they travel through the water as well as over waves, the buoys is also bobbing up and down in the water to further complicate things. In some cases one or more of buoys light may go off or dim for any reason.

Since this is a marine environment there is also salt spray over everything, either from breaking waves, sea spray, or just evaporation of the salt water. Salt will build up on buoys' light enclosed. Another factor is that of wildlife. Birds frequently sit on top of buoys and posts and leave their excrement behind. This coupled with the possibility of a light becoming dim as its battery or light begins to reach the end of its life can very quickly shorten the visibility of the light.

During the night time there are just as many interfering variables to visibility as there are during the day time with one major addition, no main light source. There can be fog, haze, rain, cloudiness; glare, etc... are night just as there can be during the day. This combined with the above variables can lower the visibility of the light to easily one half of its intended visibility of one nautical mile.

In reality there will always be cases of a light that can be seen from farther distances and lights that can only be seen from closer distances based on the local weather conditions as well as many of the above mentioned factors to visibility.

\section{PROPOSED METHODOLOGY}

This paper proposes the use of GIS Mapping to graphically display the buoys that are lighted as well as the range of light that each buoy could display. Using GIS Mapping, a point was created for each buoy with the attributes of light and location. The light attribute held if the buoy had a light or not and the location was a quick description of its location. Then each lighted buoy had a range ring drawn around it and these range rings were combined to create a lit area, or the area in which a buoy or other navigational aid could be seen. The area which is over water and not covered by these shapes is where no buoy or other navigational aid is visible.

The light attribute held if the buoy had a light or not and a quick description of its location is determined. Then each lighted buoy had a range ring drawn around it and these range rings were combined to create a lit area, or the area in which a buoy or other navigational aid is visible. The area that is not covered by these shapes and is over water is where no buoy or other navigational aid is visible.

\section{APPLICATION OF PROPOSED METHODOLOGY}

The proposed methodology is applied to the main part of the Great South Bay in NY which is a shallow bay located on the south shore of Long Island and is bordered by a barrier island to the south. The eastern edge is defined as the Robert Moses parkway/causeway and bridge system which is located in Bay shore, NY. The western boundary is defined as the Smiths Point Bridge; which is located in Mastic Beach, NY. Using NOAA charts that have the location of each buoy and if it was lighted or not. Chart number 12353 and 12352 were used as the base maps for this paper. Figure 1 shows the NOAA charts number 1252 and 1253 used for implementation.

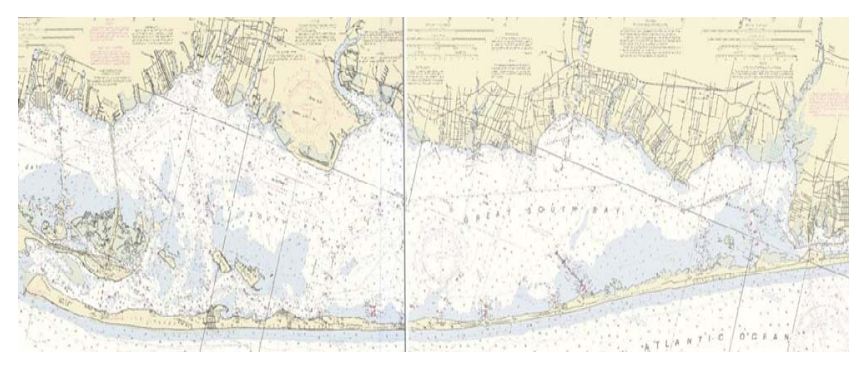

Figure 1. NOAA chart 1252 and 1253 (Base Map) 
As in figure 2 if a rectangle was to be drawn around the selected Great South Bay area the corner points of this area would be:

$$
\begin{aligned}
& \text { NW point }=40^{\circ} 41^{\prime} 3.54^{\prime \prime} \mathrm{N} \\
& \text { SW point }=40^{\circ} 37^{\prime} 33.75^{\prime \prime} \mathrm{N} \\
& \text { NE point }=40^{\circ} 45^{\prime} 47.88^{\prime \prime} \mathrm{N} \\
& \text { SE point }=40^{\circ} 43^{\prime} 56.86^{\prime \prime} \mathrm{N}
\end{aligned}
$$
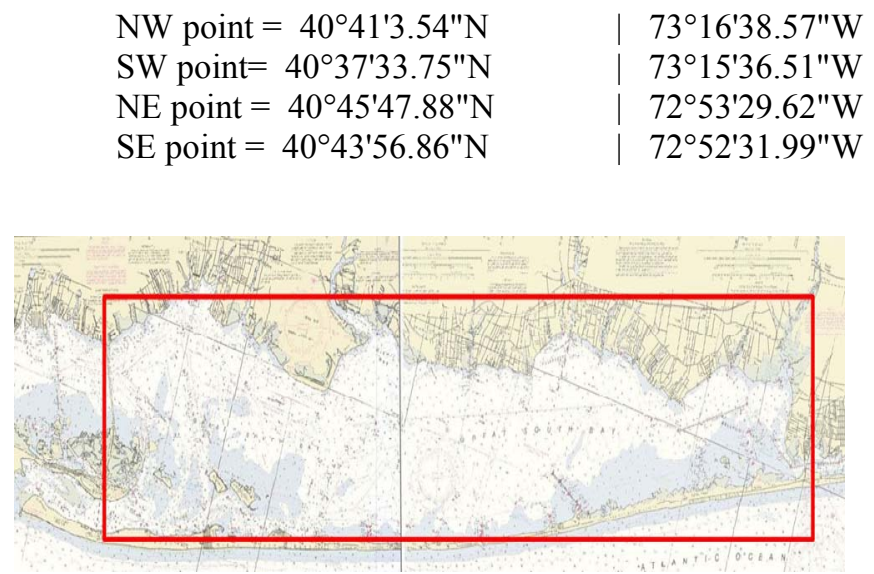

Figure 2. Great South Bay area of interest

A range of one nautical mile was first used to show the coverage of lighted buoys and navigation aids and then a range of one half of one nautical mile was used. As in figure 3, this was found to be very easy to retranslate this concept. Applying these range rings it can be seen very quickly where the problems lie.

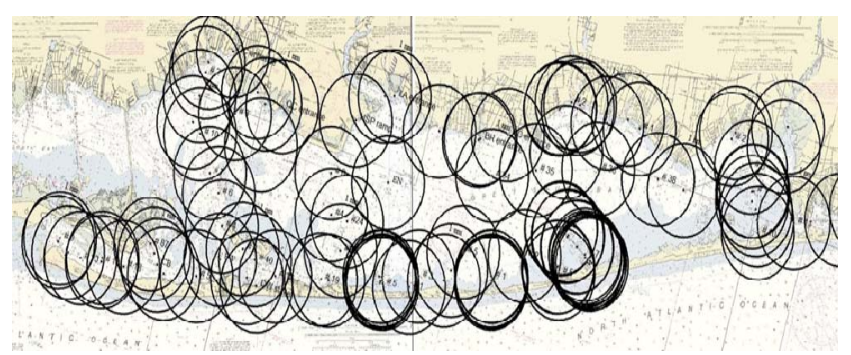

Figure 3. Application of a nautical mile ring

Under the one mile range area there are only a few spots where there is no coverage. These spots luckily are also areas of ample depth and no major obstructions for most vessels that utilize the Great South Bay. Figure 4 shows the combination of proposed range rings to form lit area.

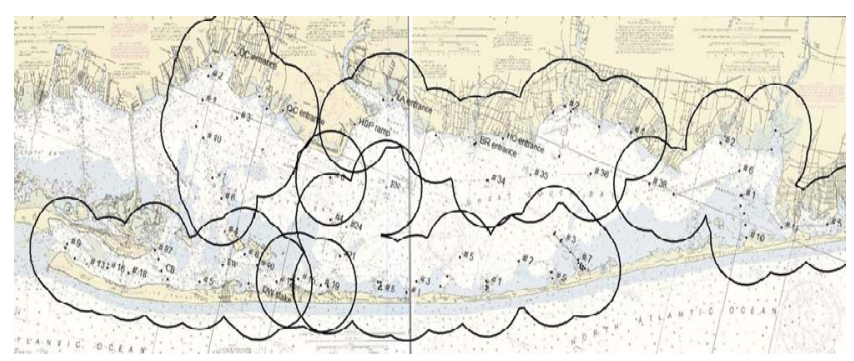

Figure 4. Combination of proposed rings to form lit area
Once the visibility is brought down to one half of one nautical mile, as it would be the practical case more often, the problem becomes much more apparent. There are many areas that do not have coverage and many of these areas have shoals and other obstructions that can create some major incidents and problems. Figure 5 shows the case of one half nautical mile visibility. It is obvious from the figure that some areas are not fully lit and consequently lack of visibility is initiated.

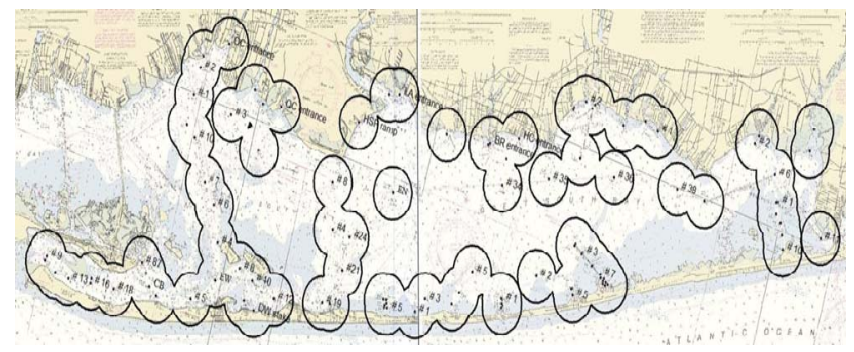

Figure 5. Half a nautical mile visibility mapping

Using our GIS Mapping methodology, it is very clear and accurate to determine which areas have visibility problems and where to install some more navigational aids (buoys) to have an adequate coverage.

\section{CONCLUSIONS AND RECOMMENDATIONS}

Based on the above findings, it is very clear to see that there are gaps between navigational aids coverage in the Great South Bay. Nowadays, mariners are relaying on their electronic devices without having the necessary navigation information about the local area and basic navigation knowledge.

In the cases where these devices may not work or malfunctions, they need to have a reliable tools and knowledge available to properly determine their location and how to navigate through. At night with the very limited visibility and other hazards of boats with non-working navigation lights this mapping methodology can easily and cheaply help make the waters on the Great South Bay a little safer at night.

From our investigation some recommendations are drawn. The addition of more lighted buoys in the trouble spots identified in this paper will be of great help to night navigation. This recommendation can be considered as a long term consideration as it will take quite some time to be put into action. It would not be an easy task to add more buoys as they will disrupt the numbering of the buoys already in place and will take revisions of charts.

Another recommendation is to increase the range of the lighted buoys with larger and more powerful lights so that they will cover more area. This will be considered an affordable short term application. In addition to the revision and maintenance of unlighted buoys, it could help supplement the coverage area and keep visibility as consistent and safe as possible. 
An independent non-profit organization could help maintain and keep the bay as safe as possible by implementing the proposed suggestions. This will require the revision of existing standard and reformulate a new standard depends on GIS mapping and makes it available for all mariners.

This GIS mapping methodology can be further extended to be applied to other bay areas and port entrances.

\section{REFERENCES}

[1] Beccardo, P., Tonolo, F. T., Ronco, F., 2003. Geogrphic Information Systems and Remote Sensing for Disaster management, Proceedings of the 6th AGILE, April, Lyon, France, 8pp.

[2] Chieko, A., Naoko, M., Masaaki, S., H. Tomita, K. Iwamura, "Management of Mapping in Local Government using Remote Sensing and the REAL TIME GIS”, IEEE 2002, International Geoscience and Remote Sensing Symposium, 0-7803-7537-8/02, 2002.

[3] C. Arai, N. Matsuda, M. Shikada, "An Application of Remote Sensing and REAL TIME GIS to Digital Map for Local Government", IEEE 2003, International Geoscience and Remote Sensing Symposium, 07803-7930-6/03, 2003.

[4] Jankowski, P., Andrienko N. and Andrienko G., 2001. Map- Centred Exploratory Approach to Multiple Criteria Spatial Decision Making, Geographical Information Science, Vol 15, No.2, pp. 101-127.

[5] Joerin, F., Golay, F., and Musy A., 1998. CIS and Multicriteria Analysis for Land Management COST-UCE Action 4 Conference, Sept 21-22, Jukkasjärvi, Kiruna, Sweden,10pp.

[6] M. Tobita, 2002. Japanese Geodetic Datum 2000 and coordinates ransformation, pp.42-64, pp.136-156.

[7] Ohlhof, T., Gülch, E., Müller, H., Wiedemann, C., Torre, M. 2000.. In International Archives of the Photogrammetry, Remote Sensing and Spatial Information Sciences, ISPRS Congress, Istanbul, July 2004. 